\title{
O romance brasileiro contemporâneo conforme os prêmios literários (2010-2014)
}

Regina Zilberman ${ }^{1}$

\section{Considerações iniciais}

Prêmios literários podem ser um excelente estímulo para o desenvolvimento de uma literatura nacional. Favorecem os escritores, ao divulgar sua obra entre o público não especializado, colaborando também para a conquista de autonomia financeira, em decorrência do valor do prêmio, se esse for pago em dinheiro, e do crescimento das vendas, das quais advêm direitos autorais. Cooperam também para conferir visibilidade a editoras que publicam os livros vencedores, e orientam os leitores, dirigindo-os para criações e criadores avaliados positivamente por um grupo credenciado de jurados.

Caso exemplar é o de Cristóvão Tezza, que, até o lançamento de $O$ filho eterno, dividia sua carreira entre a escrita de livros de ficção (contos e romances), preferencialmente, e a universidade, onde lecionava linguística. Este livro, que pode ser classificado como romance, autoficção ou autobiografia, foi publicado em 2007 e contemplado com vários prêmios, sendo os mais importantes o Jabuti 2008, o Portugal Telecom 2008, o São Paulo de Literatura 2008 e o Passo Fundo Zaffari \& Bourbon de Literatura, em 2009. A múltipla premiação valeu-lhe, na ocasião, mais de 400 mil reais, além de motivar sua adoção enquanto leitura obrigatória em provas de exame de ingresso ao ensino superior, como o vestibular à Universidade Federal do Rio Grande do Sul (UFRGS). Graças ao êxito da obra, Cristóvão Tezza pôde então dedicar-se em tempo integral à criação literária.

Nem todos os escritores foram ou serão tão bem sucedidos quanto Cristóvão Tezza, mas, de todo modo, o impulso proporcionado por um prêmio nacional respeitado pode ser determinante para a difusão e a reputação de um autor e de sua produção artística.

\footnotetext{
${ }^{1}$ Doutora em letras e professora na Universidade Federal do Rio Grande do Sul (UFRGS), Porto Alegre, RS, Brasil. E-mail de contato: reginaz@portoweb.com.br
} 
A importância dos prêmios literários não é medida apenas pelo ângulo da criação e circulação de obras e seus autores. Prêmios literários também sinalizam tendências, e talvez constituam um termômetro bastante adequado para se medir o estado atual de uma literatura. $\mathrm{O}$ fato de que os principais prêmios brasileiros confiram primazia ao romance é antecipadamente um sintoma do prestígio desse gênero entre editoras e público leitor, fenômeno que pode ser equiparado à notoriedade do conto nos anos 1970, no Brasil (Dalcastagnè, 2001).

Entre 2010 e 2014, os grandes prêmios literários nacionais foram os seguintes:

a) Jabuti, criado em 1958;

b) Passo Fundo Zaffari \& Bourbon de Literatura, criado em 1997 e concedido pela primeira vez em 1999;

c) Portugal Telecom de Literatura, criado em 2003; e

d) São Paulo de Literatura, criado em 2008.

Desses, o prêmio Portugal Telecom de Literatura, enquanto mantido por aquela empresa de telefonia, ${ }^{2}$ foi concedido para poesia, conto e crônica, e romance. Também o Jabuti divide-se em várias categorias e gêneros, entre os quais figura o romance. Por sua vez, os prêmios Passo Fundo Zaffari \& Bourbon de Literatura e São Paulo de Literatura destinam-se exclusivamente a romances, o que confirma a hipótese de que esse gênero recebe uma distinção especial entre as possíveis manifestações da arte literária.

Cabe, ainda, lembrar de dois outros dois prêmios - o da Academia Brasileira de Letras, que contempla a categoria "ficção", ainda que predomine o romance entre os laureados, e o da Biblioteca Nacional, que, desde 2008, confere o Prêmio Machado de Assis ao melhor romance. A diferença entre essas duas últimas premiações e as anteriores é que aquelas instituições não procedem à divulgação dos inscritos, nem dos finalistas, informando unicamente aos ganhadores.

${ }^{2}$ Em 2015, o Portugal Telecom foi substituído pelo Oceanos, passando a ser patrocinado pelo Instituto Itaú Cultural. 
Pode-se supor, pois, que o romance constitui a face mais visível e valorizada da literatura brasileira contemporânea. E que examinar quais deles são premiados colabora para se entender o que - em termos de autores e obras - é considerado mais representativo da produção atual.

\section{Os resultados}

Com o objetivo de verificar que romances receberam maior número de indicações aos prêmios mencionados, tomou-se como ponto de partida a relação de finalistas dos concursos promovidos pelas seguintes entidades: Portugal Telecom, Governo de São Paulo, Câmara Brasileira do Livro, Zaffari \& Bourbon, Academia Brasileira de Letras e Biblioteca Nacional, que, em sua variedade, representam instituições privadas, públicas e organizações não governamentais. Verificamos quais obras apareceram com mais frequência na condição de finalistas a cada ano. Os quadros de 1 a 5, a seguir, registram as obras mais indicadas a cada ano.

QUADRO 1 - Finalistas com ao menos uma indicação (2010)

\begin{tabular}{|c|l|l|}
\hline Indicações & \multicolumn{1}{|c|}{ Romance } & \multicolumn{1}{c|}{ Autor* } \\
\hline 5 & - Outra vida n.a. & Rodrigo Lacerda \\
\hline 4 & \multicolumn{1}{|c|}{ n.a. } \\
\hline \multirow{5}{*}{3} & - O filho da mãe & \multicolumn{1}{c|}{ Bernardo Carvalho } \\
\cline { 2 - 3 } & - A passagem tensa dos corpos & Carlos de Brito e Mello \\
\cline { 2 - 3 } & - Leite derramado & Chico Buarque \\
\hline \multirow{5}{*}{2} & - Sinuca embaixo d'água & Carol Bensimon \\
\cline { 2 - 3 } & - Se eu fechar os olhos agora & Edney Silvestre \\
\cline { 2 - 3 } & - O albatroz azul & João Ubaldo Ribeiro \\
\cline { 2 - 3 } & - Estive em Lisboa e lembrei de vocêe & Luiz Ruffato \\
\cline { 2 - 3 } & - A minha alma é irmã de Deus & Raimundo Carrero \\
\cline { 2 - 3 } & - Pornopopeia & Reinaldo Moraes \\
\hline 1 & - O livro dos mandarins & Ricardo Lísias \\
\hline
\end{tabular}

Fonte: dados da pesquisa.

Obs.: n.a. = não se aplica.

Nota: * Havendo coincidência no número de indicações, a relação de obras aparece por ordem alfabética de autores. 
QUADRO 2 - Finalistas com ao menos uma indicação (2011)

\begin{tabular}{|c|l|l|}
\hline Indicações & \multicolumn{1}{|c|}{ Romance } & \multicolumn{1}{c|}{ Autor $^{*}$} \\
\hline 4 & - Passageiro do fim do dia & Rubens Figueiredo \\
\hline 3 & - Cidade Livre & João Almino \\
\hline \multirow{5}{*}{2} & - Azul-corvo & Adriana Lisboa \\
\cline { 2 - 3 } & - Paisagem com dromedário & Carola Saavedra \\
\cline { 2 - 3 } & - Nada a dizer & Elvira Vigna \\
\cline { 2 - 3 } & - Minha mãe se matou sem dizer adeus & Evandro Affonso Ferreira \\
\cline { 2 - 3 } & - Do fundo do poço se vê a lua & Joca Reiners Terron \\
\cline { 2 - 3 } & - Ribamar & José Castello \\
\hline \multirow{4}{*}{1} & - O Dom do crime & Marco Lucchesi \\
\cline { 2 - 3 } & - Bolero de Ravel & Menalton Braff \\
\cline { 2 - 3 } & - Chá das cinco com o vampiro & Miguel Sanches Neto \\
\hline
\end{tabular}

Fonte: dados da pesquisa.

Nota: * Havendo coincidência no número de indicações, a relação de obras aparece por ordem alfabética de autores.

QUADRO 3 - Finalistas com ao menos uma indicação (2012)

\begin{tabular}{|c|l|l|}
\hline Indicações & \multicolumn{1}{|c|}{ Romance } & \multicolumn{1}{c|}{ Autor* } \\
\hline 5 & - Habitante irreal & Paulo Scott \\
\hline 4 & \multicolumn{1}{|c|}{ n.a. } & n.a. \\
\hline \multirow{5}{*}{3} & - Infâmia & Ana Maria Machado \\
\cline { 2 - 3 } & - Procura do romance & Julián Fuks \\
\cline { 2 - 3 } & - O passeador & Luciana Hidalgo \\
\cline { 2 - 3 } & - Domingos sem Deus & Luiz Ruffato \\
\cline { 2 - 3 } & - Diário da queda & Michel Laub \\
\hline \multirow{5}{*}{} & - A vendedora de fósforos & Adriana Lunardi \\
\cline { 2 - 3 } & - O senhor do lado esquerdo & Alberto Mussa \\
\cline { 2 - 3 } & - Vermelho amargo & Bartolomeu Campos Queirós \\
\cline { 2 - 3 } & - K & Bernardo Kucinski \\
\cline { 2 - 3 } & - Oestranho no corredor & Chico Lopes \\
\cline { 2 - 3 } & - Herança de Maria & Domingos Pellegrini \\
\cline { 2 - 3 } & - Uma duas & Eliane Brum \\
\cline { 2 - 3 } & - Don Solidon & Helio Pólvora \\
\cline { 2 - 3 } & - Perdição & Luiz Vilela \\
\cline { 2 - 3 } & - Tapete de silêncio & Menalton Braff \\
\cline { 2 - 3 } & - Dois rios & Tatiana Salem Levy \\
\hline
\end{tabular}

Fonte: dados da pesquisa.

Obs.: n.a. $=$ não se aplica.

Nota: * Havendo coincidência no número de indicações, a relação de obras aparece por ordem alfabética de autores. 
QUADRO 4 - Finalistas com ao menos uma indicação (2013)

\begin{tabular}{|c|c|c|}
\hline Indicações & Romance & Autor* \\
\hline \multirow{3}{*}{4} & - Barba ensopada de sangue & Daniel Galera \\
\hline & - O que deu para fazer em matéria de... & Elvira Vigna \\
\hline & - O céu dos suicidas & Ricardo Lísias \\
\hline 3 & - O mendigo que sabia de cor... & Evandro Affonso Ferreira \\
\hline \multirow{11}{*}{2} & - As visitas que hoje estamos & Antonio Geraldo F. Ferreira \\
\hline & - Caderno de ruminações & Francisco Dantas \\
\hline & - Solidão continental & João Gilberto Noll \\
\hline & - O sonâmbulo amador & José Luiz Passos \\
\hline & - Quiçá & Luisa Geisler \\
\hline & - Era meu esse rosto & Marcia Tiburi \\
\hline & - A máquina de madeira & Miguel Sanches Neto \\
\hline & - Mar azul & Paloma Vidal \\
\hline & - Estive lá fora & Ronaldo Correia de Brito \\
\hline & - Sagrada família & Xico Sá \\
\hline & - Big Jato & Zuenir Ventura \\
\hline \multirow{5}{*}{1} & - Deus foi almoçar & Ferréz \\
\hline & - Pauliceia de mil dentes & Maria José Silveira \\
\hline & - O casarão da rua do Rosário & Menalton Braff \\
\hline & - O que os cegos estão sonhando & Noemi Jaffe \\
\hline & - Desde que o samba é samba & Paulo Lins \\
\hline
\end{tabular}

Fonte: dados da pesquisa.

Nota: * Havendo coincidência no número de indicações, a relação de obras aparece por ordem alfabética de autores.

QUADRO 5 - Finalistas com ao menos uma indicação (2014)

\begin{tabular}{|c|l|l|}
\hline Indicações & \multicolumn{1}{|c|}{ Romance } & \multicolumn{1}{c|}{ Autor* } \\
\hline \multirow{4}{*}{4} & - Nossos ossos & Marcelino Freire \\
\cline { 2 - 3 } & - Opisanie swiata & Veronica Stigger \\
\hline \multirow{5}{*}{3} & - Reprodução & Bernardo Carvalho \\
\cline { 2 - 3 } & - A maçã envenenada & Michel Laub \\
\cline { 2 - 3 } & - O drible & Sérgio Rodrigues \\
\hline \multirow{5}{*}{2} & - Hanói & Adriana Lisboa \\
\cline { 2 - 3 } & - Lívia e o cemitério africano & Alberto Martins \\
\cline { 2 - 3 } & - Barreira & Amilcar Bettega \\
\cline { 2 - 3 } & - A cidade, o inquisidor e os ordinários & Carlos de Brito e Mello \\
\cline { 2 - 3 } & - O frio aqui fora & Flávio Cafiero \\
\cline { 2 - 3 } & - Aos 7 e aos 40 & João Anzanello Carrascoza \\
\cline { 2 - 3 } & - A tristeza extraordinária do... & Joca Reiners Terron \\
\hline
\end{tabular}




\begin{tabular}{|l|l|l|}
\hline \multirow{4}{*}{} & - O bibliotecário do imperador & Marco Lucchesi \\
\cline { 2 - 3 } & - O evangelho segundo Hitler & Marcos Peres \\
\cline { 2 - 3 } & - A república das abelhas & Rodrigo Lacerda \\
\cline { 2 - 3 } & - Na escuridão, amanhã & Rogério Pereira \\
\hline \multirow{2}{*}{1} & - Anel de vidro & Ana Luísa Escorel \\
\cline { 2 - 3 } & - Divórcio & Ricardo Lísias \\
\hline
\end{tabular}

Fonte: dados da pesquisa.

Nota: * Havendo coincidência no número de indicações, a relação de obras aparece por ordem alfabética de autores.

Estabelecidos os quadros de frequência de indicação das obras por ano, coube conferir atenção aos autores das obras selecionadas. Aparecem os seguintes nomes, destacando primeiramente os que aparecem apenas uma vez nas listas no período escolhido: ${ }^{3}$ Adriana Lunardi; Alberto Martins; Alberto Mussa; Amilcar Bettega; Ana Luísa Escorel; Ana Maria Machado; Antonio Geraldo Figueiredo Ferreira; Bartolomeu Campos Queirós; Bernardo Kucinski; Carol Bensimon; Carola Saavedra; Chico Buarque; Chico Lopes; Daniel Galera; Domingos Pellegrini; Edney Silvestre; Eliane Brum; Ferrez; Flávio Cafiero; Francisco Dantas; Helio Pólvora; João Almino; João Anzanello Carrascoza; João Gilberto Noll; João Ubaldo Ribeiro; José Castello; José Luiz Passos; Julián Fuks; Luciana Hidalgo; Luisa Geisler; Luiz Vilela; Marcelino Freire; Marcia Tiburi; Marcos Peres; Maria José Silveira; Noemi Jaffe; Paloma Vidal; Paulo Lins; Paulo Scott; Raimundo Carrero; Reinaldo Moraes; Rogério Pereira; Ronaldo Correia de Brito; Rubens Figueiredo; Sérgio Rodrigues; Tatiana Salem Levy; Veronica Stigger; Xico Sá; Zuenir Ventura.

Foram escolhidos por mais de uma vez para ocupar a posição de finalista os seguintes romancistas, considerando o período entre 2010 e 2014:4 Adriana Lisboa; Bernardo Carvalho; Carlos de Brito e Mello; Elvira Vigna; Evandro Affonso Ferreira; Joca Reiners Terron; Luiz Ruffato; Marco Lucchesi; Michel Laub; Miguel Sanches Neto; Rodrigo

\footnotetext{
${ }^{3}$ Alguns desses autores foram premiados por seus romances em outros períodos, como Alberto Martins (Portugal Telecom, em 2006), Amilcar Bettega (Portugal Telecom, em 2005), Chico Buarque (Jabuti, Melhor Livro de Ficção, em 2004; Passo Fundo Zaffari \& Bourbon de Literatura, em 2005), João Gilberto Noll (Jabuti, em 2005; Portugal Telecom, em 2009), Ronaldo Correia de Brito (Prêmio São Paulo, em 2009), Tatiana Salem Levy (Prêmio São Paulo, em 2008).

${ }^{4}$ Em período anterior, Bernardo Carvalho recebeu o Portugal Telecom (2003) e o Jabuti (2004).
} 
Lacerda. Por sua vez, Menalton Braff e Ricardo Lísias ${ }^{5}$ foram indicados por três vezes.

Ainda que a relação seja diversificada, somando mais de 60 nomes, pode-se constatar que quase $20 \%$ deles se repetem, sugerindo que se trata de um sistema estável, com sujeitos autores que se mantiveram produtivos no período.

Essa relação pode ser examinada a partir da perspectiva dos gêneros. Identificam-se 16 escritoras pertencentes ao sexo feminino: Adriana Lisboa, Adriana Lunardi, Ana Luísa Escorel, Ana Maria Machado, Carol Bensimon, Carola Saavedra, Eliane Brum, Elvira Vigna, Luciana Hidalgo, Luisa Geisler, Marcia Tiburi, Maria José Silveira, Noemi Jaffe, Paloma Vidal, Tatiana Salem Levy, Veronica Stigger.

Por sua vez, são 46 os autores pertencentes ao sexo masculino: Alberto Martins, Alberto Mussa, Amilcar Bettega, Antonio Geraldo Figueiredo Ferreira, Bartolomeu Campos Queirós, Bernando Kucinski, Bernardo Carvalho, Carlos de Brito e Mello, Chico Buarque, Chico Lopes, Daniel Galera, Domingos Pellegrini, Edney Silvestre, Evandro Affonso Ferreira, Ferrez, Flávio Cafiero, Francisco Dantas, Helio Pólvora, João Almino, João Anzanello Carrascoza, João Gilberto Noll, João Ubaldo Ribeiro, Joca Reiners Terron, José Castello, José Luiz Passos, Julián Fuks, Luiz Ruffato, Luiz Vilela, Marcelino Freire, Marco Lucchesi, Marcos Peres, Menalton Braff, Michel Laub, Miguel Sanches Neto, Paulo Lins, Paulo Scott, Raimundo Carrero, Reinaldo Moraes, Ricardo Lísias, Rodrigo Lacerda, Rogério Pereira, Ronaldo Lima Lins, Rubens Figueiredo, Sérgio Rodrigues, Xico Sá, Zuenir Ventura. Verifica-se, pois, o predomínio do gênero masculino, que corresponde a $75 \%$ dos indicados.

A repartição étnica, por sua vez, indica a presença de apenas dois escritores negros - Paulo Lins e Ferréz - cada um com uma única indicação. Não se constata a presença de autoras afrobrasileiras entre as finalistas selecionadas entre 2010 e 2014.

Para o exame da procedência geográfica, bem como a faixa etária dos autores, procedemos a uma segunda seleção, privilegiando aqueles que tinham recebido pelo menos três indicações no ano em que figuraram como finalistas. O quadro 6, a seguir, relaciona os nomes conforme o ano de nascimento, ordenando-os do mais idoso ao mais jovem, colocando-se

\footnotetext{
${ }^{5}$ Ricardo Lísias recebeu também o prêmio Portugal Telecom em 2006.
} 
à direita, em duas colunas, respectivamente a cidade onde nasceu e a cidade em que cada um deles reside.

QUADRO 6 - Autores(as) com três indicações ou mais entre os finalistas, por ano de nascimento, cidade de nascimento e cidade de residência

\begin{tabular}{|c|c|c|c|}
\hline Nome & Ano & Cidade de nascimento & Cidade de residência \\
\hline Ana Maria Machado & 1941 & Rio de Janeiro & Rio de Janeiro \\
\hline Chico Buarque & 1944 & Rio de Janeiro & Rio de Janeiro \\
\hline Evandro A. Ferreira & 1945 & Araxá, MG & São Paulo \\
\hline Elvira Vigna & 1947 & Rio de Janeiro & Rio de Janeiro \\
\hline João Almino & 1950 & Mossoró, RN & \begin{tabular}{|l|} 
Exterior \\
\end{tabular} \\
\hline Rubens Figueiredo & 1956 & Rio de Janeiro & Rio de Janeiro \\
\hline Bernardo Carvalho & 1960 & Rio de Janeiro & Rio de Janeiro/São Paulo \\
\hline Luiz Ruffato & 1961 & Cataguases, MG & São Paulo \\
\hline Sérgio Rodrigues & 1962 & Muriaé, MG & $\begin{array}{l}\text { Rio de Janeiro } \\
\end{array}$ \\
\hline Luciana Hidalgo & 1965 & Rio de Janeiro & Rio de Janeiro \\
\hline Paulo Scott & 1966 & Porto Alegre & Rio de Janeiro \\
\hline Marcelino Freire & 1967 & Sertânia, PE & São Paulo \\
\hline Rodrigo Lacerda & 1969 & Rio de Janeiro & São Paulo \\
\hline Michel Laub & 1973 & Porto Alegre & São Paulo \\
\hline Veronica Stigger & 1973 & Porto Alegre & São Paulo \\
\hline $\begin{array}{l}\text { Carlos de Brito e } \\
\text { Mello }\end{array}$ & 1974 & Belo Horizonte & Belo Horizonte \\
\hline Ricardo Lísias & 1975 & São Paulo & São Paulo \\
\hline Daniel Galera & 1979 & São Paulo/Porto Alegre & São Paulo/Porto Alegre \\
\hline Julián Fuks & 1981 & São Paulo & São Paulo \\
\hline
\end{tabular}

Fonte: dados da pesquisa.

A seleção mais restrita não altera a divisão dos gêneros, já que se mantém o predomínio dos autores pertencentes ao sexo masculino. Por sua vez, podem-se identificar, em ambos os gêneros, a preponderância de dois núcleos geográficos:

1) Rio de Janeiro, onde nasceram ou residem há algum tempo (em ordem alfabética) Ana Maria Machado, Chico Buarque, Elvira Vigna, Luciana Hidalgo, Paulo Scott, Rubens Figueiredo e Sérgio Rodrigues; e

2) São Paulo, onde nasceram e residem há algum tempo (em ordem alfabética) Bernardo Carvalho, Daniel Galera (alternadamente com 
Porto Alegre), Evandro Affonso Ferreira, Julián Fuks, Luiz Ruffato, Marcelino Freire, Michel Laub, Ricardo Lísias, Rodrigo Lacerda e Veronica Stigger.

Apenas dois escritores não se localizam nesse eixo geográfico:

- João Almino, que, tendo nascido no Rio Grande do Norte, dividese entre Brasília e o exterior, em decorrência de sua carreira na diplomacia brasileira;

- Carlos de Brito e Mello, de Belo Horizonte.

Examinado a distribuição etária por meio do último quadro, observase que os autores dividem-se em dois grandes grupos, constituído o primeiro por aqueles que nasceram entre 1940 e 1959, e o segundo por aqueles que nasceram entre 1960 e 1980 (quadro 7).

QUADRO 7 - Distribuição etária de autores(as) com três indicações ou mais entre os finalistas

\begin{tabular}{|l|l|c|}
\hline & \multicolumn{1}{|c|}{ Nome } & Ano de nascimento \\
\hline \multirow{4}{*}{$\begin{array}{l}\text { Grupo 1: nascidos } \\
\text { entre 1940 e 1959 }\end{array}$} & Ana Maria Machado & 1941 \\
\cline { 2 - 3 } & Chico Buarque & 1944 \\
\cline { 2 - 3 } & Evandro A. Ferreira & 1945 \\
\cline { 2 - 3 } & Elvira Vigna & 1947 \\
\cline { 2 - 3 } & João Almino & 1950 \\
\cline { 2 - 3 } & Rubens Figueiredo & 1956 \\
\hline \multirow{5}{*}{$\begin{array}{l}\text { Grupo 2: nascidos } \\
\text { entre 1960 e 1980 }\end{array}$} & Bernardo Carvalho & 1960 \\
\cline { 2 - 3 } & Luiz Ruffato & 1961 \\
\cline { 2 - 3 } & Sérgio Rodrigues & 1962 \\
\cline { 2 - 3 } & Luciana Hidalgo & 1965 \\
\cline { 2 - 3 } & Paulo Scott & 1966 \\
\cline { 2 - 3 } & Marcelino Freire & 1967 \\
\cline { 2 - 3 } & Rodrigo Lacerda & 1969 \\
\cline { 2 - 3 } & Michel Laub & 1973 \\
\cline { 2 - 3 } & Veronica Stigger & 1973 \\
\cline { 2 - 3 } & Carlos de Brito e Mello & 1974 \\
\cline { 2 - 3 } & Ricardo Lísias & 1975 \\
\cline { 2 - 3 } & Daniel Galera & 1979 \\
\cline { 2 - 3 } & Julián Fuks & 1981 \\
\hline
\end{tabular}

Fonte: dados da pesquisa. 
No que diz respeito à separação etária, constata-se que a maioria dos finalistas e ganhadores de prêmios pertence à geração mais jovem, sendo que metade desse segundo grupo nasceu depois dos anos 1970. Cabe, então, verificar a contribuição desse grupo de vencedores à ficção brasileira contemporânea.

\section{Traços predominantes}

O exame do conteúdo dos romances avaliados como melhores pelos distintos concursos supõe a abordagem das obras pela perspectiva de sua composição, considerando tema, enredo, personagens, perspectiva narrativa, espaço e tempo (Genette, 1972; Halperin, 1974; Lefebve, 1975; Martin, 1986; Reis, 1995), bem como sua integração a uma modalidade de narrativa (Bakhtin, 1984; Hutcheon, 1988).

Ainda que a esfera de autores premiados seja restrita diante do quadro mais amplo da ficção nacional, o universo se mostra bastante vasto quando se trata do exercício da análise de cada um dos títulos. Torna-se necessária, pois, uma segunda seleção, que se fez a partir de dois recortes e um cruzamento. O primeiro recorte, semelhante ao que permitiu a definição das datas de nascimento e local de residência, levou em conta os autores que receberam três ou mais indicações no ano em que figuraram como finalistas; o segundo privilegiou os que se destacaram nas listas mais de uma vez em anos distintos. Cruzadas as duas relações, chegou-se aos seguintes romancistas e suas obras finalistas, arrolados em ordem alfabética de nome no quadro 8.

QUADRO 8 - Obras selecionadas para determinação dos traços predominantes

\begin{tabular}{|l|l|l|}
\hline & \multicolumn{1}{|c|}{ Nome } & \multicolumn{1}{c|}{ Romances } \\
\hline 1 & Bernardo Carvalho & $\begin{array}{l}\text { - O filho da mãe } \\
- \text { Reprodução }\end{array}$ \\
\hline 2 & Carlos de Brito e Mello & $\begin{array}{l}\text { - A passagem tensa dos corpos } \\
- \text { A cidade, o inquisidor e os ordinários }\end{array}$ \\
\hline 3 & Elvira Vigna & $\begin{array}{l}- \text { Nada a dizer } \\
- \text { O que deu para fazer em matéria de história de } \\
\text { amor }\end{array}$ \\
\hline 4 & Evandro Affonso Ferreira & $\begin{array}{l}- \text { O mendigo que sabia de cor os adágios de Erasmo } \\
\text { de Rotterdam } \\
- \text { Minha mãe se matou sem dizer adeus }\end{array}$ \\
\hline
\end{tabular}




\begin{tabular}{|l|l|l|}
\hline 5 & Luiz Ruffato & $\begin{array}{l}\text { - Estive em Lisboa e lembrei de você } \\
- \text { Domingos sem Deus }\end{array}$ \\
\hline 6 & Michel Laub & $\begin{array}{l}- \text { Diário da queda } \\
- \text { A maçã envenenada }\end{array}$ \\
\hline 7 & Ricardo Lísias & $\begin{array}{l}\text {-O livro dos mandarins } \\
- \text { O céu dos suicidas } \\
- \text { Divórcio }\end{array}$ \\
\hline 8 & Rodrigo Lacerda & $\begin{array}{l}\text { - Outra vida } \\
- \text { A república das abelhas }\end{array}$ \\
\hline
\end{tabular}

Fonte: dados da pesquisa.

Logo, oito escritores - sendo sete deles do sexo masculino, e uma autora do sexo feminino, residentes entre Rio de Janeiro, São Paulo e Belo Horizonte, e pertencendo todos à etnia caucasiana - e 17 romances podem sugerir que aspectos constituem as facetas mais valorizadas no contexto da literatura contemporânea nacional, na segunda década do terceiro milênio.

Para reconhecer essas facetas de modo sintético, serão levados em conta os elementos indicados: modalidade de romance escolhido; características dos(as) protagonistas; perspectiva narrativa; espaço e tempo da ação; e tema preponderante.

Predominam, entre as escolhidas, as obras que podem ser classificadas como autoficção (Hutcheon, 1980; Lejeune, 1994; Gasparini, 2011), gênero que talvez remonte aos anos 1960 (A paixão segundo $G H$, de Clarice Lispector, por exemplo, talvez pudesse ser assim considerada), mas que alcançou um grau de intensidade, na literatura ocidental, a partir dos anos 1990. Ricardo Lísias, o mais premiado dos autores pertencentes a esse grupo, pratica o gênero em dois dos romances arrolados: $O$ céu dos suicidas e Divórcio. Também o memorialismo fictício aparece entre os livros preferidos, sendo matéria de Michel Laub, em Diário da queda e A maçã envenenada, bem como de A república das abelhas, de Rodrigo Lacerda, que flerta, de certo modo, com o romance histórico (Lukács, 1966; Hutcheon, 1988), ao recuperar a trajetória política de Carlos Lacerda, jornalista e ex-governador do Estado da Guanabara (hoje Estado do Rio de Janeiro), entre 1960 e 1965.

Relacionado ao gênero escolhido entre a paleta de possibilidades que oferece o romance contemporâneo, está o emprego da perspectiva autodiegética (Genette, 1972). Mas essa é recorrente também em outras obras, apontando para a elevada frequência dos discursos do eu (Galle e 
Olmos, 2009). Encontra-se, assim, no relato retrospectivo de Carlos de Brito e Mello, em A passagem tensa dos corpos, no estilo confessional empregado por Elvira Vigna em Nada a dizer e $O$ que deu para fazer em matéria de história de amor, ou no monólogo interior de $O$ mendigo que sabia de cor os adágios de Erasmo de Rotterdam e de Minha mãe se matou sem dizer adeus, os dois de Evandro Affonso Ferreira.

Os romances dos autores mais premiados compartilham características relativamente uniformes no que se refere às personagens que lideram a ação ficcional, tal como apresentado a seguir.

a) Em 13 desses romances as figuras masculinas constituem os entes mais importantes da trama; e apenas os enredos de Elvira Vigna conferem protagonismo a uma mulher, que ocupa também a posição de narradora principal.

b) De modo quase invariável, as personagens que levam a trama à frente vinculam-se à etnia caucasiana.

c) Em geral, as personagens principais situam-se em uma faixa etária que oscila entre 30 e 45 anos. Minha mãe se matou sem dizer adeus, de Evandro Affonso Ferreira, expõe o monólogo de um homem idoso, mas constitui exceção no quadro dos vencedores dos prêmios.

d) A maioria dos protagonistas, como seria de se esperar, nasceu no Brasil, de preferência em grandes cidades. Foge à regra a personagem central de $O$ filho da mãe, de Bernardo Carvalho, cuja ação se passa sobretudo entre a Rússia e a Tchetchênia.

e) Do ponto de vista profissional, a maioria dos protagonistas pertence ao universo das letras: há escritores/as, como os que registram $O$ que deu para fazer em matéria de história de amor, de Elvira Vigna, e $O$ céu dos suicidas e Divórcio, de Ricardo Lísias; e também quase-escritores, como o que comparece em $O$ mendigo que sabia de cor os adágios de Erasmo de Rotterdam, de Evandro Affonso Ferreira. Encontram-se, ainda, jornalistas, como nos romances de Michel Laub; intelectuais, como em Minha mãe se matou sem dizer adeus, de Evandro Affonso Ferreira; e mesmo políticos, como o que relata seu passado em $A$ república das abelhas, de Rodrigo Lacerda, que se destaca por sua cultura e participação no mundo da 
imprensa. A exceção é representada pelo romance Outra vida, centrado em uma personagem vinculada a uma empresa estatal.

f) O recorte social dos protagonistas é consequência direta de sua atuação profissional: pertencem à classe média e não experimentam problemas de falta de dinheiro ou de emprego. Os romances premiados de Luiz Ruffato, sobretudo Domingos sem Deus, retratam a classe trabalhadora, mas esse caso ocupa a posição de exceção. Por sua vez, Estive em Lisboa e lembrei de você apresenta uma personagem que não se enquadra na classe média brasileira, mas também não pertence ao segmento operário, compondo parte de sua trajetória a busca de algum tipo de ascensão ou enriquecimento, com a emigração para Portugal após problemas sentimentais experimentados pelo herói e narrador.

g) Os protagonistas não constituíram uma família - com exceção do que conduz a ação em Outra vida, de Rodrigo Lacerda - ou têm um(a) companheiro(a), sem a presença de filhos, situação representada sobretudo em romances em que o adultério é o tema predominante. Mesmo em $O$ filho da mãe, de Bernardo Carvalho, o herói é um solitário, e a mãe, mencionada no título, é uma figura distante, assim como seu irmão.

h) O espaço onde transcorre a trama é, de modo quase absoluto, urbano. Eventualmente as ações se desdobram em pequenas cidades, como em A passagem tensa dos corpos, de Carlos de Brito e Mello, mas a preferência recai sobre a localização do enredo em grandes capitais brasileiras - Rio de Janeiro ou São Paulo - ou em metrópoles internacionais, como a São Petersburgo de $O$ filho da mãe, de Bernardo Carvalho, ou, pelo menos, cidades europeias, como em Estive em Lisboa e lembrei de você, de Luiz Ruffato. Nações estrangeiras são a Rússia e Tchetchênia, locais da ação de $O$ filho da mãe, assim como a China, onde acontece boa parte dos eventos de O livro dos mandarins, de Ricardo Lísias, e para onde almeja dirigirse o herói de Reprodução, de Bernardo Carvalho.

i) Da perspectiva da temporalidade, é marcante a escolha pelo presente, entendido esse como tempo verbal e como cronologia. Mesmo em relatos memorialistas, como o Diário da queda, de Michel Laub, a atualidade não é apenas o ponto do qual parte o retrospecto 
do narrador, mas o problema que ele pretende resolver no agora de sua situação. $\mathrm{O}$ emprego do presente enquanto tempo verbal sugere que a ação transcorre simultaneamente à sua manifestação verbal, conforme uma concomitância própria aos discursos do eu característicos do estilo autodiegético selecionado. Porém, até um romance como Outra vida, relatado em terceira pessoa, desenrola-se enquanto os fatos são expostos ficcionalmente. Em A cidade, o inquisidor e os ordinários, de Carlos de Brito e Mello, a opção pelo formato dramático, em que a sucessão de diálogos afiança a exclusão da diegese, verifica-se outra possibilidade do "eterno presente" que os romances elegem. A colagem de histórias curtas que particulariza Domingos sem Deus, de Luiz Ruffato, é igualmente um modo de evitar a utilização do tempo pretérito, conforme uma concepção que, em certo sentido, anula o passado e neutraliza a história.

Essas marcas, de ordem estrutural, resultam provavelmente dos temas que prevalecem nas tramas, que tratam, na maioria, de problemas individuais, como o adultério (em Nada a dizer, de Elvira Vigna, em Divórcio, de Ricardo Lísias, em $O$ mendigo que sabia de cor os adágios de Erasmo de Rotterdam, de Evandro Affonso Ferreira, e em Outra vida, de Rodrigo Lacerda), a (ir)realização pessoal (em Estive em Lisboa e lembrei de você, de Luiz Ruffato e em O livro dos mandarins, de Ricardo Lísias), a culpa (em Diário da queda e A maçã envenenada, de Michel Laub), a busca da identidade (em O filho da mãe, de Bernardo Carvalho). Temas de ordem social e política são menos frequentes, representados quase que exclusivamente, neste grupo, por A cidade, o inquisidor e os ordinários, de Carlos de Brito e Mello. A história política nacional é matéria de A república das abelhas, de Rodrigo Lacerda, ainda que o faça desde a ótica exclusiva do narrador póstumo, o que relativiza as possibilidades de interpretação ou denúncia dos procedimentos da classe dirigente do país.

Pode-se cogitar que o predomínio dos temas e das questões propostas relaciona-se, de uma parte, às preocupações da geração que, nessa segunda metade do século XXI, produz ficção no Brasil, nascida a maioria, como se observou, depois dos anos 1970. Logo, apareceram no horizonte da cultura nacional após terem sido superados os ciclos da literatura social e da ficção de cunho regionalista que se estendeu entre os anos 1930 e 1960, bem como 
a tendência à exposição dos dramas políticos decorrentes da ditadura militar e da repressão político-ideológica, entre 1970 e 1980.

Assim, mesmo os escritores nascidos nos anos 1940 buscam caminhos inovadores no contexto da ficção brasileira, contrapondo-se à tradição de representação político-social que os antecedeu. $\mathrm{O}$ tipo de experimentalismo associado à produção desses romancistas coloca-os em paradigmas mais globalizados e menos localistas, sintonizados simultaneamente a gêneros literários em evidência, como a autoficção, a paródia dos modelos tradicionais (Bakhtin, 1981; Bakhtine, 1978), o investimento da intertextualidade (Kristeva, 1969) e o memorialismo (fictício ou não).

Os prêmios literários não inventam seus resultados, mas evidenciam as orientações adotadas por um grupo de escritores - residentes nos dois maiores centros brasileiros, na maioria homens e relativamente jovens representativos ambos, orientações e escritores, do romance brasileiro desta década em curso.

\section{Considerações finais}

Relações de vencedores em concursos literários nem sempre são considerados objeto de pesquisa, mas a relevância das distinções outorgadas confere às obras notoriedade e agregam a elas valor econômico no mercado livreiro. Não por outra razão as editoras dos livros ganhadores acrescentam às capas, às abas ou aos releases informações sobre os prêmios de que foram alvo seus editados, sejam os criadores, sejam suas criações.

O respeito conquistado pelos prêmios literários - os internacionais Nobel de Literatura (Suécia, desde 1901), Goncourt (França, desde 1896), Pulitzer (Estados Unidos, desde 1917), Man Booker (Inglaterra, desde 1968), Camões (Portugal e Brasil, desde 1988), entre outros, ou os nacionais, como os aqui indicados -, advém da confiabilidade dos júris escolhidos, da remuneração e da honraria conferidas aos vencedores, além da tradição consolidada.

Para o pesquisador de literatura, prêmios concedidos a obras literárias, considerando a data em que aquelas foram publicadas, têm uma qualidade a mais: sinalizam quais livros alcançaram mais visibilidade no ano em que apareceram no mercado editorial e consumidor. As listas de best-seller apontam antecipadamente os destaques da atualidade, mas elas não levam em conta a possível qualidade estética que os livros elencados 
possam ter. Por seu turno, as relações de finalistas ou de vencedores de premiações sugerem que as obras carregam consigo algum valor artístico, independentemente da fama de seu autor, do local onde tenham sido editadas, do número de volumes comercializados. Por isso, tais listas estão habilitadas a fornecer informações sobre o estado atual de uma literatura - ou de um gênero literário - e sobre os aspectos julgados mais significativos pelos formadores da opinião no campo cultural, para a aferição de suas virtudes estéticas.

No caso da literatura nacional, parece evidente que é o romance o gênero que, com mais facilidade, não apenas inscreve um criador no sistema literário, como tem condições de alavancar seu renome, quando ele ainda não for famoso ou estiver no ostracismo, ou então confirmar a celebridade de que disfruta.

Outros gêneros literários não são desqualificados, mas não parecem propiciar aos artistas similar inserção em um contexto artístico mais amplo. Há poucos concursos dirigidos a peças dramáticas publicadas em formato de livro, sendo as distinções oferecidas às suas encenações, que nem sempre requerem um texto prévio, supondo muitas vezes improvisações ou intervenções. O gênero poético não perdeu seu prestígio, que cresceu à medida que perdeu especialistas no seu estudo. Talvez por isso, na maioria dos casos, não alcance conciliar o aspecto aurático com que ainda são celebrizados os escritores e o lado comercial da produção literária, já que poucos poetas podem se regozijar com o fato de se sustentarem unicamente com a venda de seus livros de versos.

O conto viveu sua era dourada entre o final dos anos 1960 e 1970. À época do endurecimento da ditadura militar, foi o gênero que, no campo literário, conseguiu romper com as limitações artísticas e culturais impostas pela censura e pelo silenciamento dos intelectuais. Abriu as portas para uma nova geração de escritores, de que fizeram parte, entre outros, Ignácio de Loyola Brandão, Moacyr Scliar e Rubem Fonseca, promovidos, muitos deles, por prestigiados concursos como o organizado, na época, pelo governo do Estado do Paraná. A paulatina distensão política facultou, poder-se-ia dizer até mimeticamente, o alongamento dos textos escritos, permitindo a consolidação do romance. Esse, contudo, não é apenas uma preferência nacional, pois muitos dos prêmios internacionais mencionados são destinados exclusivamente a romances. 
Da sua parte, os concursos brasileiros permitem, em um exercício de especulação, desenhar o romance ideal para os jurados nacionais. Certamente, não se aplica a todos os casos vencedores, mas, à primeira vista, foi válido durante o quinquênio entre 2010 e 2014. Esse romance ideal poderia ser assim descrito: seu autor pertenceria ao sexo masculino; teria nascido ou residiria atualmente em São Paulo ou no Rio de Janeiro; enquadrar-se-ia à etnia caucasiana; sua idade oscilaria entre 35 e 45 anos, um pouco para mais ou para menos. Daria primazia à autoficção ou, ao menos, a uma narrativa em primeira pessoa, transcorrendo a ação de preferência no "aqui e agora" do discurso, pois, mesmo que relembre fatos do passado e tente exorcizá-los, é sua situação presente do sujeito da enunciação que está em jogo.

Esse narrador, pertencente ao sexo masculino, integraria a etnia caucasiana e compartilharia a idade do autor do romance. Como esse, residiria em uma grande metrópole, provavelmente Rio de Janeiro ou São Paulo; tanto melhor se a trama puder inseri-lo em um cenário estrangeiro, de preferência distante. E teria aspirações a escritor, ou já exerceria essa profissão de alguma maneira, na condição de ficcionista ou poeta, jornalista ou homem de letras, professor ou intelectual. Como faria parte da classe média, poderia não ser muito abastado, mas, como também não teria familiares, não necessitaria preocupar-se com questões econômicas, o que facilitaria sua mobilidade social ou profissional.

A solidão do protagonista, ou pelo menos o enfraquecimento das relações domésticas e, às vezes, até afetivo-amorosas, facultaria à intriga dispensar outras personagens fortes ou relevantes; também não seria imprescindível introduzir tramas paralelas, alargando o escopo do enredo. Como também é próprio à maioria dos romances vencedores a ausência de contraponto de personagens, reduzindo a margem dos conflitos, o enredo seria deixado por conta dos vagares interiores e exteriores do protagonista.

Ao privilegiar um protótipo de romance nacional, possivelmente se esteja estereotipando a ficção brasileira da segunda década do século XXI. De todo modo, os prêmios literários falam, e provavelmente seja isso que eles comuniquem. Talvez valha a pena ouvi-los enquanto outra voz para além da academia e da crítica - a se manifestar sobre a literatura. 


\section{Referências}

BAKHTIN, Mikhail (1981). Problemas da poética de Dostoievski. Tradução de Paulo Bezerra. Rio de Janeiro: Forense.

BAKHTIN, Mikhail (1984). Les genres du discours. In: BakhtinE, Mikhaïl. Esthétique de la création verbale. Paris: Gallimard.

BAKHTINE, Mikhaill (1978). Esthétique et théorie du roman. Paris, Gallimard.

DALCASTAGNÈ, Regina (2001). Renovação e permanência: o conto brasileiro da última década. Estudos de Literatura Brasileira Contemporânea, Brasília, n. 11, p. 3-17, jan./fev.

GALLE, Helmut; OLMOS, Ana Cecília (2009). Em primeira pessoa: abordagens de uma teoria da autobiografia. São Paulo: Annablume; Fapesp.

GASPARINI, Philippe (2011). Autoficcion vs autobiographie. Tangence, n. 97, p. 11-24. Disponível em: https://goo.gl/gMxdct. Acesso em: 5 out 2015.

GENETTE, Gérard (1972). Figures III. Paris: Seuil.

HALPERIN, John (Ed) (1974). The theory of the novel. Nova York; Londres: Oxford University Press.

HUTCHEON, Linda (1980). Narcisistic narrative: the metaficcional paradox. Waterloo: Wilfrid Laurier University Press.

HUTCHEON, Linda (1988). A poetics of Postmodernism. History, Theory, Fiction. Nova York; Londres: Routledge.

KRISTEVA, Julia (1969). Le mot, le dialogue et le roman. In: KRISTEVA, Julia. Semeiotiquè. Recherches pour une sémanalyse. Paris: Seuil.

LEFEBVRE, Maurice-Jean (1975). Estrutura do discurso da poesia e da narrativa. Tradução de José Carlos Seabra Pereira. Coimbra: Almedina.

LEJEUNE, Philippe (1994). El pacto autobiográfico y otros estudios. Tradução de Ana Torrent. Madri: Megazul-Endymion.

LUKÁCS, Georg (1966). La novela historica. Tradução de Jasmin Reuter. México: Era.

MARTIN, Wallace (1986). Recent theories of narrative. Londres: Cornell University Press.

REIS, Carlos (1995). O conhecimento da literatura. Coimbra: Almedina. 
Recebido em março de 2016.

Aprovado em julho de 2016.

\section{resumo/abstract/resumen}

\section{O romance brasileiro contemporâneo conforme os prêmios literários (2010-2014)}

Regina Zilberman

Os prêmios literários destinados a obras publicadas, cujos concursos foram realizados na primeira e na segunda década do século XXI, têm privilegiado o romance. Os júris responsáveis pelas premiações são constituídos por críticos literários, escritores e estudiosos da literatura, qualificando os livros escolhidos. Examiná-los faculta compreender o que, em termos de autores e obras, é considerado mais representativo da ficção atual brasileira. Para chegar a esse resultado, elegeu-se o período de cinco anos (2010-2014) de premiações concedidas a romances nacionais, destacando-se os autores e as obras mais frequentes, o que permite identificar quais são os nomes mais assíduos, a que gênero, etnia e faixa etária pertencem os ficcionistas, e de que parte do país eles provêm ou onde residiam à época de produção do livro vencedor. Recortando, entre os vencedores, os mais repetidos, examinam-se as obras, considerando os aspectos relativos à modalidade de romance escolhido, às características dos protagonistas, à perspectiva narrativa, ao espaço e ao tempo da ação, bem como ao tema mais saliente.

Palavras-chave: prêmios literários, romance, autoficção, narração autodiegética.

\section{The contemporary Brazilian novel according to the literary awards (2010-2014)}

Regina Zilberman

Literary awards for published works, that participated in contests held in the first and second decades of the 21th century, have foregrounded the novel. Juries responsible for the awards are constituted by literary critics, writers and literary scholars, who categorize the chosen books. Therefore to examine the winning novels provides an understanding of what is judged more representative within contemporary Brazilian literary fiction. In order to come to these conclusions, we examined a period of five years (2010-2014) of awards granted to Brazilian novels. Such examination enables us to identify the most frequent authors and works, highlighting aspects as such as the author's gender, ethnicity and age group, as well as the region of Brazil they live or from which they originated. It also allows us to 
consider the structural aspects of the prizewinning novels, such as the modality chosen, the nature of the protagonists, the point of view, the space and time of the action as well as the most noteworthy themes.

Keywords: literary awards, novel, autofiction, autodiegetic narrative.

\section{La novela brasileña contemporánea de acuerdo con los premios literarios (2010-2014)}

Regina Zilberman

Los premios literarios que se destinan a obras publicadas, cuyos concursos fueron realizados en la primera y en la segunda década del siglo XXI, han privilegiado al género de la novela. Los jurados responsables son conformados por críticos literarios, escritores y estudiosos de la literatura, lo que indica la calidad de los libros seleccionados. Examinarlos permite comprender lo que es considerado más representativo en la ficción actual brasileña en materia de autores y obras. Para llegar a ese resultado se eligió un periodo de cinco años (2010-2014) de premios concedidos a novelas nacionales, dando importancia a los autores y a las obras más frecuentes. Ésto permite identificar cuáles son los nombres más asiduos, de que género, etnia y edad son los fabuladores, de que parte del país son provenientes, o donde vivían en la época de la producción del libro ganador. Separando los ganadores más repetidos, se examinan las obras considerando los aspectos relacionados a la modalidad de la novela elegida, a las características de los protagonistas, a la perspectiva narrativa, al espacio y al tiempo de la acción, así como también al tema más importante.

Palabras clave: premios literarios, novela, autoficción, narrador autodiegetico. 